\title{
Estimation of Concrete Strength in Structures by the BOSS Method
}

\author{
Tohru Shinozaki ${ }^{1}$, Kazutoshi Fujii ${ }^{2}$, Torao $\mathrm{Kemi}^{3}$ and Kazuhisa Shirayama ${ }^{4}$
}

Received 15 October 2003, accepted 6 April 2004

\begin{abstract}
The Broken-Off Specimens by Splitting - BOSS method was first formulated in 1985 by professor Shirayama of the University of Tsukuba. This new estimation method for concrete strength in structures has been studied subsequently by the authors in terms of practical applications. These included a simplified method and experiments under various conditions to ensure the accuracy of the test method. As a result, a standard test method with a regression equation for estimating the concrete strength in structures was proposed. Compiling these results, this paper deals with a comparative study of BOSS strength and core strength in a full-scale model structure, variance analysis of influences of sampling height and water- cement ratio of concrete on these compressive strength, and applicability of the BOSS method on the basis of these studies. High correlation was found between BOSS and core strength both in normal and high-strength concrete, and the proposed estimation equation was found to be applicable to the reliable evaluation of concrete strength in structures.
\end{abstract}

\section{Introduction}

Demand for long-life concrete structures has grown particularly due to emphasis on the preservation of the global environment and resources, an area where evaluation of the soundness of concrete structures plays a significant role.

The evaluation criteria for the soundness of structures include the compressive strength of concrete in structure. Therefore, an effective monitoring technique capable of assessing the residual strength and degradation degree is needed. The compressive strength of drilled core concrete specimen sampled from structures, hereafter referred to as core strength, has been considered as the most reliable strength of concrete in structures, and is often used in the seismic diagnosis and verification of core strength with design strength. The core strength, however, may involve several problems associated with core sampling. First, damages to structures such as voids left in concrete and amputation of reinforcing bars may result in harming the performance of the structure. Next, the number and position of sampling are limited, and execution of sampling and associated repairs are not always easy.

This led to the use of small-sized cores with a diameter of less than $50 \mathrm{~mm}$ which may reduce damage to structures (Kunimoto et al 2000 ; Terada et al 2001). On the other hand, non-destructive methods of estimating con-

\footnotetext{
${ }^{1}$ Manager, Technical Research Institute, Toda Construction Co. Ltd.

E-mail: tohru.shinozaki@toda.co.jp

${ }^{2}$ Vice President, Technical Research Institute, P.S. Mitsubishi Construction Co. Ltd.

${ }^{3}$ Professor (former), Ashikaga Institute of Technology

${ }^{4}$ Professor emeritus, University of Tsukuba
}

crete strength in structures such as the Schmidt hammer method, the ultrasonic pulse method, and an improved method that combines these two methods, have been used thanks to their ease of use (Soshiroda et al 2000). However, non-destructive methods are currently playing a supplementary role in the estimation of concrete strength in structures because they are obviously indirect methods, the test apparatus is not standardized, and the precision is significantly influenced by the conditions of the concrete in each structure, such as the type of aggregate, the mix proportions, ages, and moisture content.

We have thus proposed the BOSS method capable of estimating concrete strength in structures based on the concrete strength directly tested without causing damage to the structure (Shirayama et al 1986, 1986, 1991; Shinozaki et al 1987, 1992, 1996, 1998, 1999).

\section{BOSS specimen}

The BOSS (Broken Off Specimen by Splitting) specimen refers to a concrete specimen molded monolithically as the projected part on the surface of a structure. The BOSS specimen is a rectangular prism in shape that measures $100 \times 100 \times 200 \mathrm{~mm}$ and is to be cast in a mold consisting of steel plates with a thickness of $1.2 \mathrm{~mm}$, as shown in Fig. 1.

This Boss mold is attached to a formwork of the structure in advance. When concrete is placed into the form of structure, the BOSS mold can also be filled up with the concrete for the structure. At the time of testing, the BOSS specimen can be easily sampled by being split off from the structure without harming it, realizing ease of execution of testing and subsequent repair. The shape, dimensions and method of sampling are shown in Fig. 2.

The BOSS specimen is molded as a projected part of the concrete structure from the surface, and at the time of testing, it can be sampled directly by breaking it off from the structure, like the core method. However, unlike the 


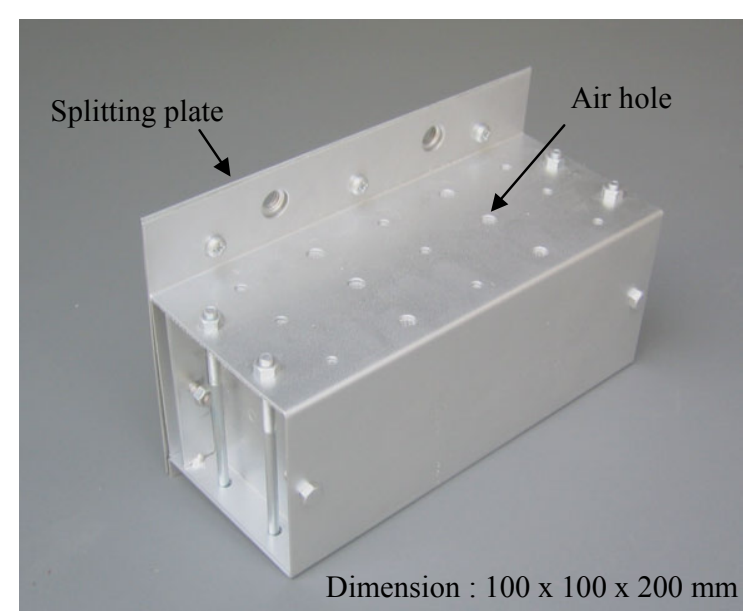

Fig. 1 BOSS specimen mold.

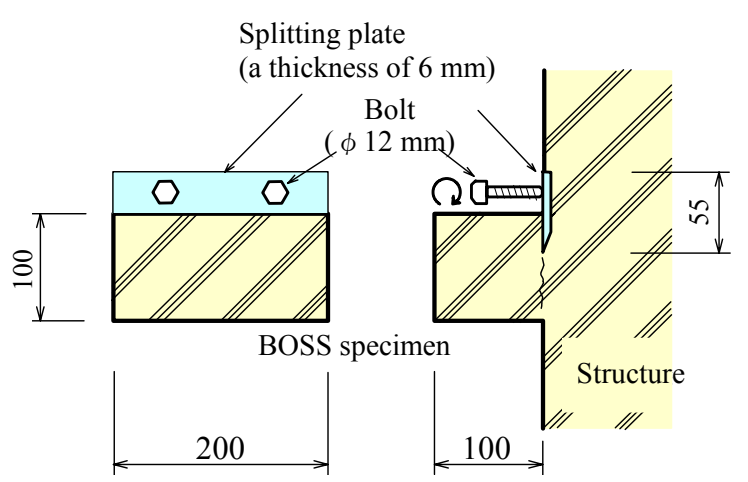

Fig. 2 Shape dimension and splitting of BOSS specimen (in millimeter).

core method, the original structural sections are not lost.

Using model wall structures, the applicability of the BOSS method to the assessment of the concrete strength in structures was studied in a variety of aspects: influences of sampling method on strength, influences of water-cement ratio and sampling height on mechanical properties, and variance analysis of the correlation between BOSS strength and core strength (Shinozaki et al 2002).

Further, in the studies aiming at extending the applicability of the BOSS method for high-strength concrete, it was considered that development of concrete strength at early ages may be affected by a high temperature history due to the higher unit cement content (Aragane et al 1998) of such concrete. Model columns were made by high-strength concrete and they were thermally insulated to have the BOSS specimens undergo an equivalent temperature history to that of the model column on the basis of the previous report by the authors (Shinozaki et al 1996). The compressive strengths of both BOSS specimens and core specimens, sampled from the same model column of high-strength concrete, were compared, and the applicability of the BOSS method to the high-strength concrete was confirmed in an experimental manner (Shinozaki et al 2002).

Centering on the BOSS method to estimate concrete strength in structures, this paper deals with a wide spec- trum of experiments, from normal concrete to ultra high-strength concrete, and compiles the data of all the experiments including reexamination of the past data with particular reference to applicability.

Estimation of the compressive strength of concrete in structures using BOSS specimens, placed monolithically at the same time, same place and subsequently cured under the same environment as those of the concrete structure, can be performed without harming the main structure, like NDT (Non-Destructive Testing methods), with sufficient precision and reliability like destructive tests such as the drilled core strength test.

The BOSS specimens enable us to estimate not only the compressive strength of concrete in structures but also mixture proportions and durability parameters such as carbonation depth, and chloride content, showing the possibility of non-destructive and comprehensive estimation of concrete quality in structures of buildings and public works through the use of BOSS specimens.

\section{Compressive strength test using BOSS}

Based on our previous studies, a proposed test method of compressive strength using BOSS specimens for estimating the strength of concrete in structures was specified as follows and used in this experiment. The BOSS method procedure is shown in Fig. 3. The BOSS method can be expected to minimize the effect of human factors on the test result and hence lead to a more reliable result. The applicable range of strength estimation through the BOSS method, as confirmed in experiments, is from 20 to $120 \mathrm{~N} / \mathrm{mm}^{2}$.

An opening $255 \mathrm{~mm}$ wide and $135 \mathrm{~mm}$ high can be provided in a sheathing board, and after being composed into the formwork of a structure, the BOSS mold can be installed in the opening from the outside. At the top of the

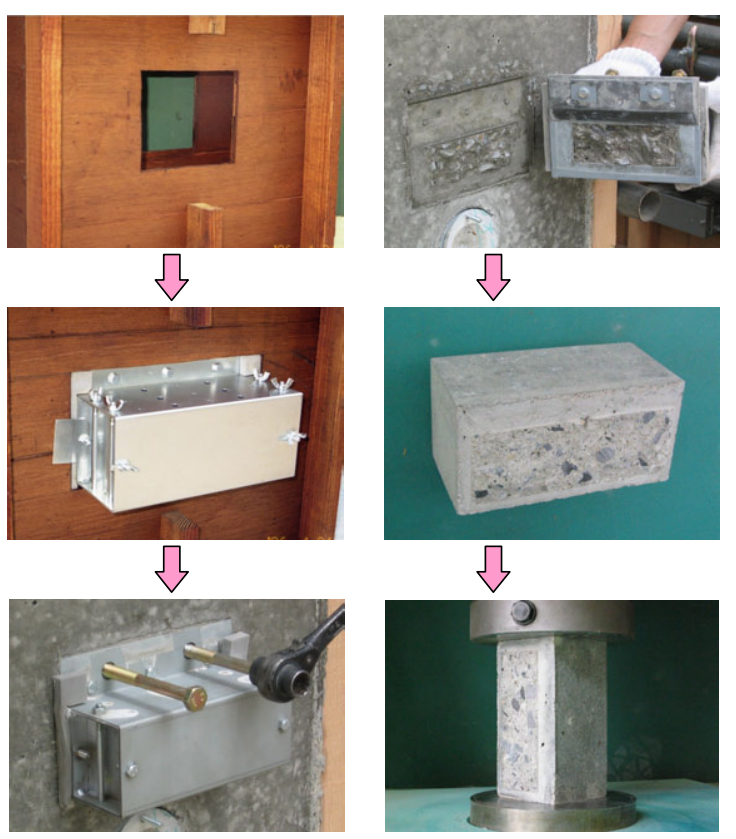

Fig. 3 The procedure of BOSS method. 
BOSS mold, fifteen holes with a diameter of $8 \mathrm{~mm}$ are drilled to release air bubbles and bleeding water. The flatness of each end of the BOSS specimen is less than $0.02 \mathrm{~mm}$, enabling the execution of the compressive strength test without grinding.

Tamping with a mallet five times is necessary when the BOSS mold is filled up with concrete. Because the BOSS specimen remains projected on the main structure until the age of the strength test, it will likely be considerably affected by the outdoor air when demolded together with the sheathing of the main formwork.

Thus the BOSS mold must be cured, until the age of strength test, in a sealed condition after the demolding of the main formwork to keep the environmental conditions as close as possible to the concrete of the main structure. The BOSS specimen can be sampled, as shown in Fig. 2, using a lever mechanism of two advancing bolts with a diameter of $12 \mathrm{~mm}$ and a $6 \mathrm{~mm}$-thick steel slit plate installed to the BOSS mold beforehand.

The compressive strength test of the BOSS specimen is executed according to Japan Industrial standard A 1108 (Method of Test for Concrete Compressive Strength: compatible with ISO 4012- Determination of Compressive Strength of Test Specimens) except for being cured not under water and the use of each pressing plane without grinding.

Estimation of the pressing area is worked out as a product of the averaged values of the distance, measured with a slide caliper, of each plane parallel to the longitudinal axis.

A highly significant correlation was recognized, from past studies (Shirayama et al 1986,1986,1991;Shinozaki et al 1987,1992,1996,1998,1999), between core strength and BOSS strength as shown in the following regression equation,

$$
F_{c o}=a P_{b}-b,
$$

Table 1 Parameters and levels applied to the normalstrength concrete experiment.

\begin{tabular}{|c|c|}
\hline Parameters & Levels \\
\hline W/C & $45 \%, 60 \%, 70 \%$ \\
\hline Sampling method ${ }^{* 1}$ & A,B,C \\
\hline Sampling height & 5 positions ( 3 positions ${ }^{* 2}$ ) \\
\hline
\end{tabular}
Only for core specimens, possible sampling quality of good,
fair and poor.
Five points for cores and three points for BOSS.

where $\boldsymbol{F}_{\boldsymbol{c} \boldsymbol{o}}$ is the core compressive strength, $\boldsymbol{P}_{\boldsymbol{b}}$ is the BOSS compressive strength and both $\boldsymbol{a}$ and $\boldsymbol{b}$ are constants to be determined in the experiment.

When the core compressive strength is nearly equal to that in the structure, the concrete strength in the structure can be estimated from the BOSS compressive strength. The following equation (2) may be applicable as an experimental estimation equation,

$$
F_{c b}=a P_{b}-b,
$$

where $\boldsymbol{F}_{c b}$ is the concrete strength in the structure $\left(\mathrm{N} / \mathrm{mm}^{2}\right)$ estimated from the BOSS compressive strength.

\section{Application to normal concrete: Series I}

\subsection{Outline of experiment}

Confirmation of concrete strength in structures is normally done in our country according to the JIS A 1107 (Method of Test for Strength of Core and Beam from Hardened Concrete). BOSS strength refers to the JIS based core strength and comparison of the compressive strengths has been made. The concrete strength in structures shows differences depending on the water-cement ratios and the sampling height. The core

Table 2 Materials used for the concretes.

\begin{tabular}{|c|c|}
\hline Materials & \multicolumn{1}{|c|}{ Type and Properties } \\
\hline Cement & $\begin{array}{c}\text { Ordinary Portland cement } \\
\text { Density }: 3.16 \mathrm{~g} / \mathrm{m}^{3}, \text { Specific surface area }: 3280 \mathrm{~cm}^{2} / \mathrm{g}\end{array}$ \\
\hline Fine aggregate & $\begin{array}{c}\text { Crushed limestone of Nabeyama } \\
\text { Surface-dry density }: 2.66 \mathrm{~g} / \mathrm{m}^{3} \text {, Water absorption }: 1.56 \%, \mathrm{~F} . \mathrm{M}: 3.20 \\
\text { Pit sand of Katori-gun } \\
\text { Surface-dry density }: 2.58 \mathrm{~g} / \mathrm{m}^{3} \text {, Water absorption }: 1.67 \%, \mathrm{~F} . \mathrm{M}: 1.90\end{array}$ \\
\hline Coarse aggregate & $\begin{array}{c}\text { Crushed limestone of Nabeyama } \\
\text { Surface-dry density }: 2.71 \mathrm{~g} / \mathrm{m}^{3}, \text { Water absorption }: 0.71 \%\end{array}$ \\
\hline Admixture & AE water reducing agent \\
\hline
\end{tabular}

\begin{tabular}{|c|c|c|c|c|c|c|c|c|}
\hline \multirow{2}{*}{$\begin{array}{l}\mathrm{W} / \mathrm{C} \\
(\%)\end{array}$} & \multirow{2}{*}{$\begin{array}{l}\text { Air } \\
(\%)\end{array}$} & \multirow{2}{*}{$\begin{array}{l}\text { Slump } \\
(\mathrm{cm})\end{array}$} & \multirow{2}{*}{$\begin{array}{l}\text { S/a } \\
(\%)\end{array}$} & \multicolumn{5}{|c|}{ Unit amount $\left(\mathrm{kg} / \mathrm{m}^{3}\right)$} \\
\hline & & & & Cement & Water & Sand $1^{*}$ & Sand $2^{*}$ & Gravel \\
\hline 45 & \multirow{3}{*}{4.5} & \multirow{3}{*}{18} & 45.9 & 378 & 170 & 527 & 276 & 976 \\
\hline 60 & & & 48.8 & 297 & 178 & 575 & 302 & 948 \\
\hline 70 & & & 50.3 & 253 & 177 & 606 & 317 & 940 \\
\hline
\end{tabular}

Table 3 Mix proportions of the concrete.

*Sand 1 : Crushed sand, Sand 2 : Pit sand 
sampling method may also affect the results. In this experiment, the above-mentioned factors affecting the strength of core specimens and BOSS specimens are investigated.

Three model walls were made of normal concrete with different compressive strengths as detailed in Table 1. Materials used in the concretes and their mixture proportions are shown in Table $\mathbf{2}$ and $\mathbf{3}$, respectively. The shapes of the model wall and the positions of both BOSS specimens and core sampling are shown in Fig. 4.

Core specimens were sampled from five different heights, 1 to 5 , while BOSS specimens were sampled from 3 different heights, a to c. In the core sampling, three different core-bits, A, B and C, were used. Core-bit A was brand-new with a thickness of $3.5 \mathrm{~mm}$, core-bit B was an all-purpose core-bit with a thickness of $5.0 \mathrm{~mm}$ and core-bit $C$ was a used one, whose surface was intentionally roughened, with a thickness of $5.0 \mathrm{~mm}$.

Concrete was placed with a bucket and compacted with a rod type vibrator of $40 \mathrm{~mm}$ in diameter, for 15 to 30 seconds, at each $60 \mathrm{~cm}$ of the placing height.

Compressive strength test were executed at the age of 28-day according to JIS A 1108 (Method of Test for Concrete Compressive Strength).

\subsection{Result and discussion}

The core strengths at the age of 28-day are shown by the type of coring method in Table 4. The mean core strength and the standard deviation (SD) show that a slight scatter in compressive strength can be seen by the type of coring method and almost no difference in compressive strength

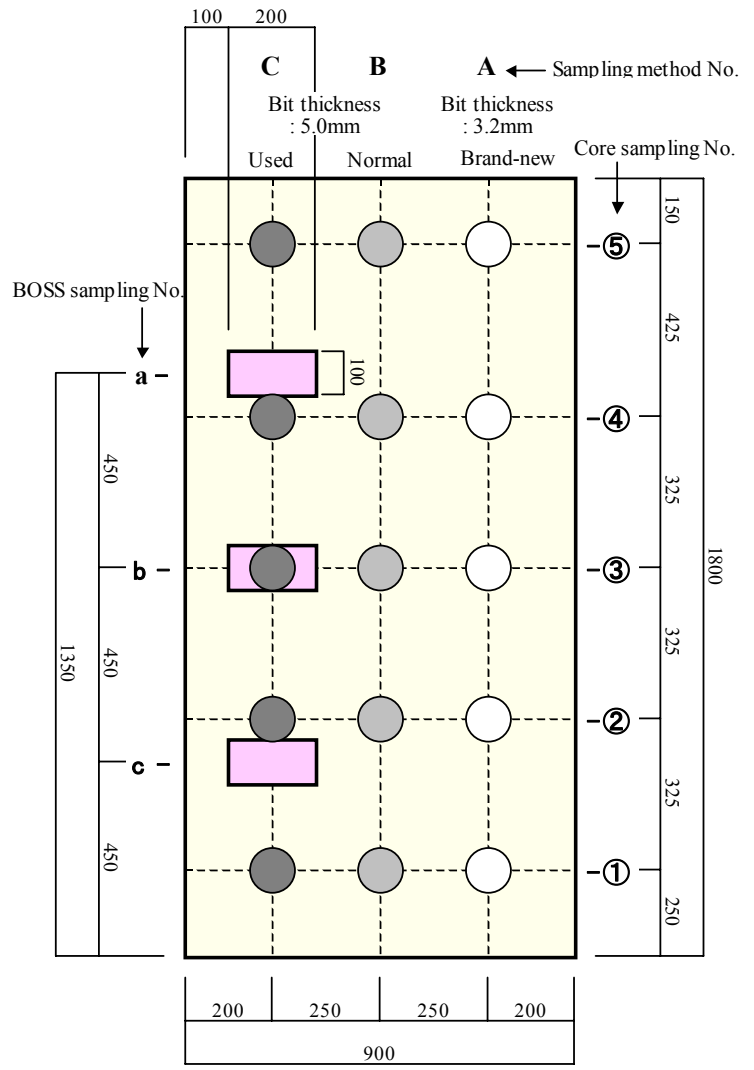

Fig. 4 Shape of the model wall and sampling positions of BOSS and cores (in millimeter).

Table 4 Difference in core strength by sampling method.

\begin{tabular}{|c|c|c|c|c|}
\hline \multirow{2}{*}{ W/C } & Sampling method & $\begin{array}{c}\text { Number of specimen } \\
(\text { sampling position) }\end{array}$ & $\begin{array}{c}\text { Average strength } \\
\left(\mathrm{N} / \mathrm{mm}^{2}\right)\end{array}$ & $\begin{array}{c}\text { SD } \\
\left(\mathrm{N} / \mathrm{mm}^{2}\right)\end{array}$ \\
\hline \multirow{3}{*}{$45 \%$} & A (good) & $5 ;(\mathrm{A} 1-\mathrm{A} 5)$ & 47.3 & 5.01 \\
\cline { 2 - 5 } & $\mathrm{B}$ (fair) & $5 ;(\mathrm{B} 1-\mathrm{B} 5)$ & 43.6 & 4.66 \\
\cline { 2 - 5 } & $\mathrm{C}$ (poor) & $5 ;(\mathrm{C} 1-\mathrm{C} 5)$ & 45.6 & 4.08 \\
\hline \multirow{3}{*}{$60 \%$} & $\mathrm{~A}$ (good) & $5 ;(\mathrm{A} 1-\mathrm{A} 5)$ & 31.8 & 5.77 \\
\cline { 2 - 5 } & $\mathrm{B}$ (fair) & $5 ;(\mathrm{B} 1-\mathrm{B} 5)$ & 30.6 & 3.29 \\
\cline { 2 - 5 } & $\mathrm{C}$ (poor) & $5 ;(\mathrm{C} 1-\mathrm{C} 5)$ & 30.0 & 4.54 \\
\hline \multirow{3}{*}{$70 \%$} & $\mathrm{~A}$ (good) & $5 ;(\mathrm{A} 1-\mathrm{A} 5)$ & 20.9 & 2.41 \\
\cline { 2 - 5 } & $\mathrm{B}$ (fair) & $5 ;(\mathrm{B} 1-\mathrm{B} 5)$ & 21.9 & 2.00 \\
\cline { 2 - 5 } & $\mathrm{C}$ (poor) & $5 ;(\mathrm{C} 1-\mathrm{C} 5)$ & 21.8 & \\
\hline
\end{tabular}

Table 5 Variance analysis of core strength.

\begin{tabular}{|c|c|c|c|c|c|c|}
\hline Parameters & $\begin{array}{l}\text { Square sum } \\
\text { of deviation }\end{array}$ & $\begin{array}{l}\text { Degree of } \\
\text { freedom }\end{array}$ & Mean square & F-value & $\mathrm{P}$-value & Result \\
\hline $\mathrm{W} / \mathrm{C}: \mathrm{A}$ & 4370.02 & 2 & 2185.01 & 525.2670 & 0.0000 & $* *$ \\
\hline Sampling method : B & 13.21 & 2 & 6.60 & 1.5873 & 0.2351 & \\
\hline Height : C & 433.57 & 4 & 108.39 & 26.0574 & 0.0000 & $* *$ \\
\hline $\mathrm{A} \times \mathrm{B}$ & 33.11 & 4 & 8.28 & 1.9896 & 0.1447 & \\
\hline $\mathrm{A} \times \mathrm{C}$ & 76.69 & 8 & 9.59 & 2.3046 & 0.0739 & \\
\hline $\mathrm{B} \times \mathrm{C}$ & 55.72 & 8 & 6.96 & 1.6743 & 0.1809 & \\
\hline Error & 66.56 & 16 & 4.16 & & & \\
\hline Total & 5048.87 & 44 & & & & \\
\hline
\end{tabular}

** : 1 percent significant, $*: 5$ percent significant 
was found by the type of core-bit.

The results of the 3-way variance analysis of water-cement ratio, type of core-bit and sampling height are shown in Table 5. Core strength is of high-level significance with respect to the water-cement ratio and sampling height, but not significant to the type of core-bit with a significance level of 0.05 , which is less than 0.2351 .

The results of the compressive strength test of BOSS specimens are shown in Fig. 5. The results of the 2-way variance analysis of BOSS strength with respect to the water-cement ratio and sampling height are shown in Table 6. The BOSS strength is of 0.01 level of significance with respect to the water-cement ratio and 0.05 level of significance with respect to the sampling height, thus showing a similar tendency to that of core strength.

The relationship between the strengths of core and BOSS is shown in Table 7. A linear regression equation can be obtained from the data in Table 7 and displayed in Fig. 6 as

$$
\boldsymbol{F}_{c o}=1.0743 \boldsymbol{P}_{b^{-1}}-475,
$$

where a high correlation of $\mathrm{R}^{2}=0.9756$ can be obtained. Both core strength and BOSS strength exhibited a similar dependency on the factors in this experiment. With a 105 experimental data obtained in the previous studies(Shinozaki et al 1998), the estimation equation (2) was worked out as

$$
\boldsymbol{F}_{c b}=1.03 \boldsymbol{P}_{b^{-}}-3.65 \text {, }
$$

while combining the data with those obtained in this experiment, shown in Table 7, equation (4) can be updated as

$$
\boldsymbol{F}_{c b}=1.017 \boldsymbol{P}_{b}-2.37 \text {. }
$$

The gradient of the line is nearly 1.0 and the difference between core strength and BOSS strength, 2.37 $\mathrm{N} / \mathrm{mm}^{2}$ given as the intersect of the line, can also be taken as a constant without regard to the concrete strength level of structures and can be rounded off to a

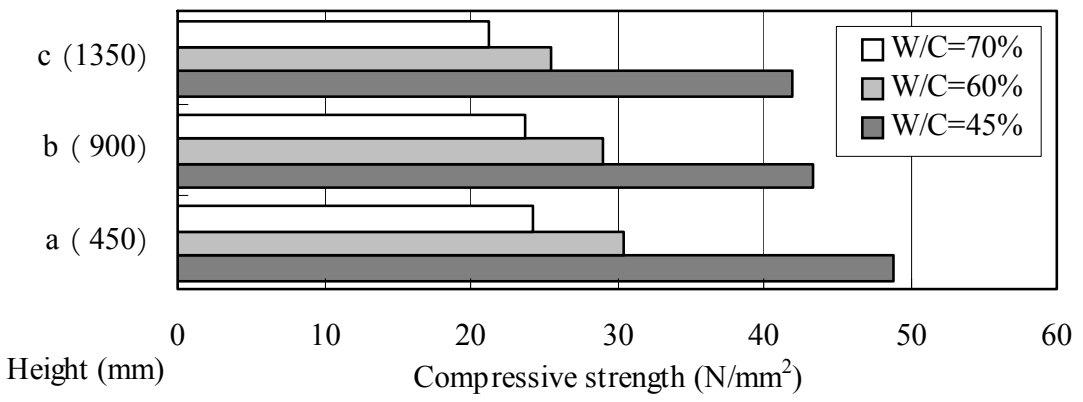

Fig. 5 Compressive strength of BOSS specimens.

Table 6 Variance analysis of BOSS strength.

\begin{tabular}{|c|c|c|c|c|c|c|}
\hline Parameters & $\begin{array}{c}\text { Square sum } \\
\text { of deviation }\end{array}$ & $\begin{array}{c}\text { Degree of } \\
\text { freedom }\end{array}$ & Mean square & F-value & P-value & Result \\
\hline W/C & 766.14 & 2 & 383.07 & 183.6293 & 0.0001 & $* *$ \\
\hline Height & 36.52 & 2 & 18.26 & 8.7521 & 0.0346 & $*$ \\
\hline Error & 8.34 & 4 & 2.09 & & & \\
\hline Total & 811.00 & 8 & & & & \\
\hline
\end{tabular}

\begin{tabular}{|c|c|c|c|c|c|c|c|}
\hline \multirow{2}{*}{$\mathrm{W} / \mathrm{C}$} & \multirow{2}{*}{$\begin{array}{l}\text { Sampling } \\
\text { position }\end{array}$} & \multicolumn{3}{|c|}{ Sampling method (Core strength) } & \multirow{2}{*}{$\begin{array}{l}\text { Core strength } \\
\qquad\left(\mathrm{N} / \mathrm{mm}^{2}\right)\end{array}$} & \multirow{2}{*}{$\begin{array}{c}\text { BOSS } \\
\text { strength } \\
\left(\mathrm{N} / \mathrm{mm}^{2}\right)\end{array}$} & \multirow{2}{*}{$\begin{array}{c}\text { Difference of } \\
\text { strength } \\
\left(\mathrm{N} / \mathrm{mm}^{2}\right)\end{array}$} \\
\hline & & A (good) & B (fair) & $\mathrm{C}$ (poor) & & & \\
\hline \multirow{3}{*}{$45 \%$} & (4) + (5) : a & 45.8 & 41.0 & 41.7 & 42.8 & 42.0 & 0.8 \\
\hline & (3) $: b$ & 43.8 & 41.4 & 46.2 & 43.8 & 43.3 & 0.5 \\
\hline & (1)+(2): $: c$ & 50.5 & 47.1 & 49.3 & 49.0 & 48.9 & 0.1 \\
\hline \multirow{3}{*}{$60 \%$} & (4) + (5) : $a$ & 26.8 & 27.7 & 26.4 & 27.0 & 25.5 & 1.5 \\
\hline & (3) : b & 33.5 & 33.4 & 32.1 & 33.0 & 29.0 & 1.0 \\
\hline & (1) + (2) : c & 35.0 & 32.7 & 33.1 & 33.6 & 30.5 & 3.1 \\
\hline \multirow{3}{*}{$70 \%$} & (4) + (5) : $a$ & 17.0 & 20.1 & 20.3 & 19.1 & 21.3 & -2.2 \\
\hline & (3) $: \mathrm{b}$ & 23.9 & 23.4 & 23.1 & 23.5 & 23.7 & -0.2 \\
\hline & (1)+(2):c & 22.4 & 22.9 & 22.8 & 22.7 & 24.2 & -1.5 \\
\hline
\end{tabular}

** $: 1$ percent significant, $*: 5$ percent significant

Table 7 Comparison of core and BOSS strength by position.

* Core strength : Average strength of three specimens or six specimens, BOSS strength : All Strength of one specimen 


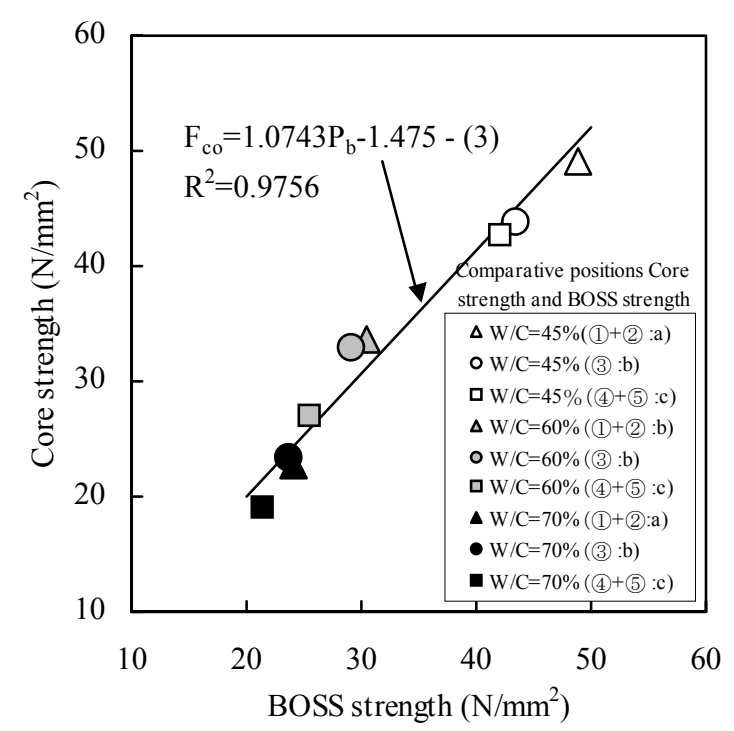

Fig. 6 Relationship between core strength and BOSS strength.

safety side as $2.5 \mathrm{~N} / \mathrm{mm}^{2}$. A simple estimation formula can be given by

$$
\boldsymbol{F}_{c b}=\boldsymbol{P}_{b^{-}} \Delta \boldsymbol{F}_{c b},
$$

where $\boldsymbol{F}_{\boldsymbol{c} b}$ is the estimated concrete strength in structure $\left(\mathrm{N} / \mathrm{mm}^{2}\right), \boldsymbol{P}_{\boldsymbol{b}}$ is the BOSS compressive strength $\left(\mathrm{N} / \mathrm{mm}^{2}\right)$, and $\Delta \boldsymbol{F}_{\boldsymbol{c} b}$ is the difference between core strength and BOSS strength $\left(2.5 \mathrm{~N} / \mathrm{mm}^{2}\right)$.

Core strengths estimated with equation (6) by substituting measured BOSS strength and measured core strength, as shown in Fig. 6, are plotted in Fig. 7. The measured core strength is slightly higher than the estimated core strength at a water-cement ratio of 0.6 , while at water-cement ratios of 0.45 and 0.7 , the measured core strength is equal to, or slightly higher than, the estimated core strength. In the previous studies, the BOSS strength was generally larger than the core strength but a scatter of 0.5 to $2.5 \mathrm{~N} / \mathrm{mm}^{2}$ was recognized in each strength. Thus the difference between measured and estimated strength in this experiment may be within the scatter range because the estimated core strength is based on one BOSS strength unlike the measured core strength, which is based on the average value of 3 or 6 cores. For more

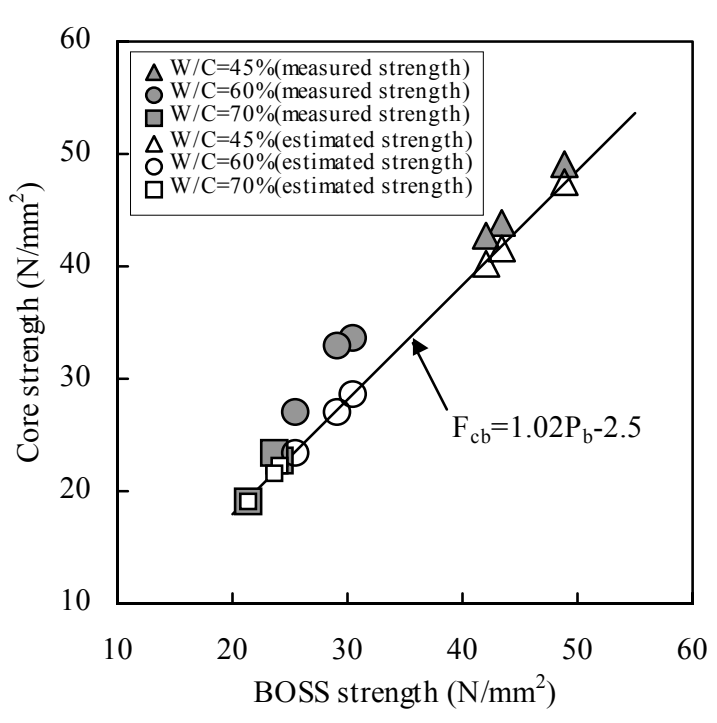

Fig. 7 Relationship between concrete strength in structure estimated by BOSS strength and core strength.

precise estimation, three BOSS specimens should be sampled and the average value should be used for estimation of concrete strength in structures. When the BOSS specimen is used for strength control in construction sites, application of equation (6) may prove to be on the safe side without overestimating the concrete strength in the structure.

\section{Application to high-strength concrete: Series II}

\subsection{Experiments}

Along with the growth in size of concrete structures, the use of high-strength concrete has become popular. The

Table 8 Parameters and levels applied to the normalstrength concrete experiment.

\begin{tabular}{|c|c|}
\hline Parameters & Levels \\
\hline W/C & $40 \%, 35 \%, 30 \%$ \\
\hline Thermal insulation $^{* 1}$ & applied, none \\
\hline Sampling position $^{* 2}$ & center , surface \\
\hline Sampling height $^{* 1}$ : BOSS specimen only, $^{* 2}$ : Core specimen
\end{tabular}

Table 9 Materials used for the concrete.

\begin{tabular}{|c|l|}
\hline Materials & \multicolumn{1}{|c|}{ Type and Properties } \\
\hline Cement & $\begin{array}{c}\text { Portland blast-furnace slag cement B type } \\
\text { Density }: 3.16 \mathrm{~g} / \mathrm{m}^{3}, \text { Specific surface area }: 3280 \mathrm{~cm}^{2} / \mathrm{g}\end{array}$ \\
\hline Fine aggregate & $\begin{array}{l}\text { Crushed limestone of Iwaki } \\
\text { Surface dry-density }: 2.63 \mathrm{~g} / \mathrm{m}^{3} \text {, Water absorption }: 0.906 \%, \text { F.M }: 3.20\end{array}$ \\
\hline Coarse aggregate & $\begin{array}{l}\text { Crushed limestone of Iwaki } \\
\text { Surface dry-density }: 2.71 \mathrm{~g} / \mathrm{m}^{3}, \text { Water absorption }: 0.683 \%\end{array}$ \\
\hline Segregation control agent & Natural polysaccharides \\
\hline Superplaticizer & Polycarboxylic acid type \\
\hline
\end{tabular}


high cement content of high-strength concrete gives rise to a high temperature history during the hydration reaction at early ages. It was pointed out that this thermal effect may affect the concrete strength(Masuda et al 2000). In this experiment, the applicability of BOSS specimens was examined when the target concrete is subjected to such high temperature history.

The parameters and grades of the experiment are shown in Table 8. The materials used for the concretes and the mixture proportions are shown in Tables 9 and 10, respectively. The shape of the model column, the position of the BOSS specimens, and the core sampling positions are shown in Fig. 8. The concretes were placed using a mobile concrete pump with a boom and they were compacted using a rod type vibrator for 5 to 10 seconds. BOSS molds covered by insulation materials as a simple adiabatic curing are shown in Fig. 9. The simple adiabatic curing was started immediately after placement of the concretes, and stopped when the BOSS specimens were sampled, by installing expanded polystyrene board with a thickness of $100 \mathrm{~mm}$ to all the planes of the mold that may be otherwise exposed to outside air. The joints of the insulation board were filled with expanded poly-

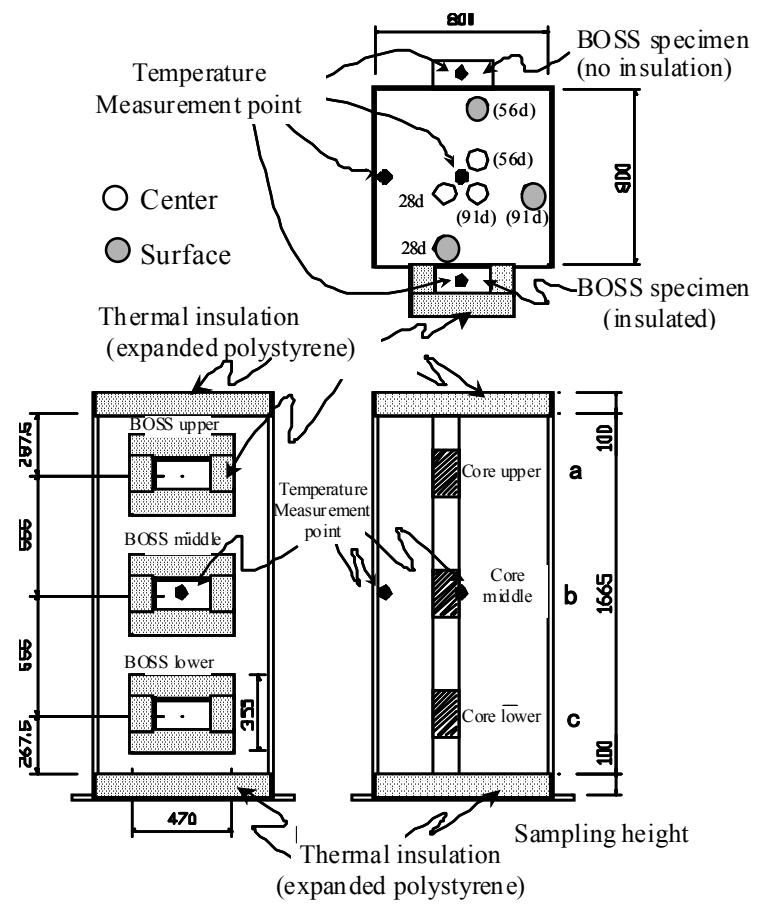

Fig. 8 Dimension and shape of the model wall (in millimeter). styrene beads. Compressive strength testing of the cores was performed according to JIS A 1107 (Method of Test for Strength of Core and Beam from Hardened Concrete).

\subsection{Results and discussions}

The properties of the fresh concretes were almost within the targeted range, with a flow value of 61.0 to $70.0 \mathrm{~cm}$ and air content of 1.8 to 2.5 percent for all the mixture designs. The temperature histories of concretes at the center and the surface of the model column and the BOSS specimens with or without adiabatic curing are shown in Fig. 10. The maximum temperatures of the model columns were higher than $60^{\circ} \mathrm{C}$ for all the mixture designs. The temperature histories of the inside of the BOSS specimens with insulation changed within a range between those of the center and the surface of the model column, and changes in the temperature gradient were similar to those of the model column. The BOSS specimens without insulation, on the other hand, underwent the influences of outdoor temperature and changed within a range between the ranges of the outdoor air and the surface of the model column, which is 25 to 30 degree lower than the maximum temperature inside of the column.

Compressive strength of the 28-day, standard-cured specimens was $51.8 \mathrm{~N} / \mathrm{mm} 2$ at a water-cement ratio of $0.4,56.5 \mathrm{~N} / \mathrm{mm} 2$ at a water-cement ratio of 0.35 and 67.5 $\mathrm{N} / \mathrm{mm} 2$ at a water-cement ratio of 0.30 .

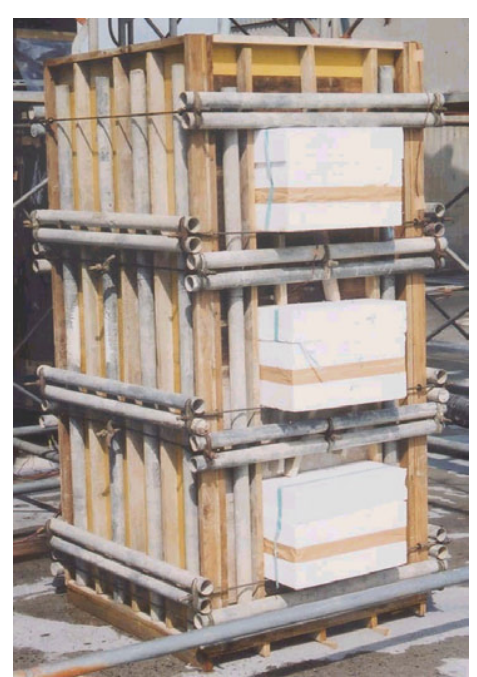

Fig. 9 Installation of BOSS molds.

Table 10 Mix proportions of the concrete.

\begin{tabular}{|c|c|c|c|c|c|c|c|}
\hline \multirow{2}{*}{$\begin{array}{c}\text { W/C } \\
(\%)\end{array}$} & \multirow{2}{*}{$\begin{array}{c}\mathrm{S} / \mathrm{a} \\
(\%)\end{array}$} & \multicolumn{4}{|c|}{ Unit amount $\left(\mathrm{kg} / \mathrm{m}^{3}\right)$} & $\begin{array}{c}\text { Segregation } \\
\text { Control agent } \\
\left(\mathrm{kg} / \mathrm{m}^{3}\right)\end{array}$ & $\begin{array}{c}\text { Superplaticizer } \\
\left(\mathrm{kg} / \mathrm{m}^{3}\right)\end{array}$ \\
\cline { 3 - 7 } & & Cement & Water & Sand & Gravel & 0.25 & 7.01 \\
\hline 40 & 51.5 & 438 & 175 & 881 & 856 & 0.25 & 8.00 \\
\hline 35 & 49.9 & 500 & 175 & 828 & 856 & 0.25 & 9.34 \\
\hline 30 & 47.6 & 584 & 175 & 755 & 856 & \\
\hline
\end{tabular}



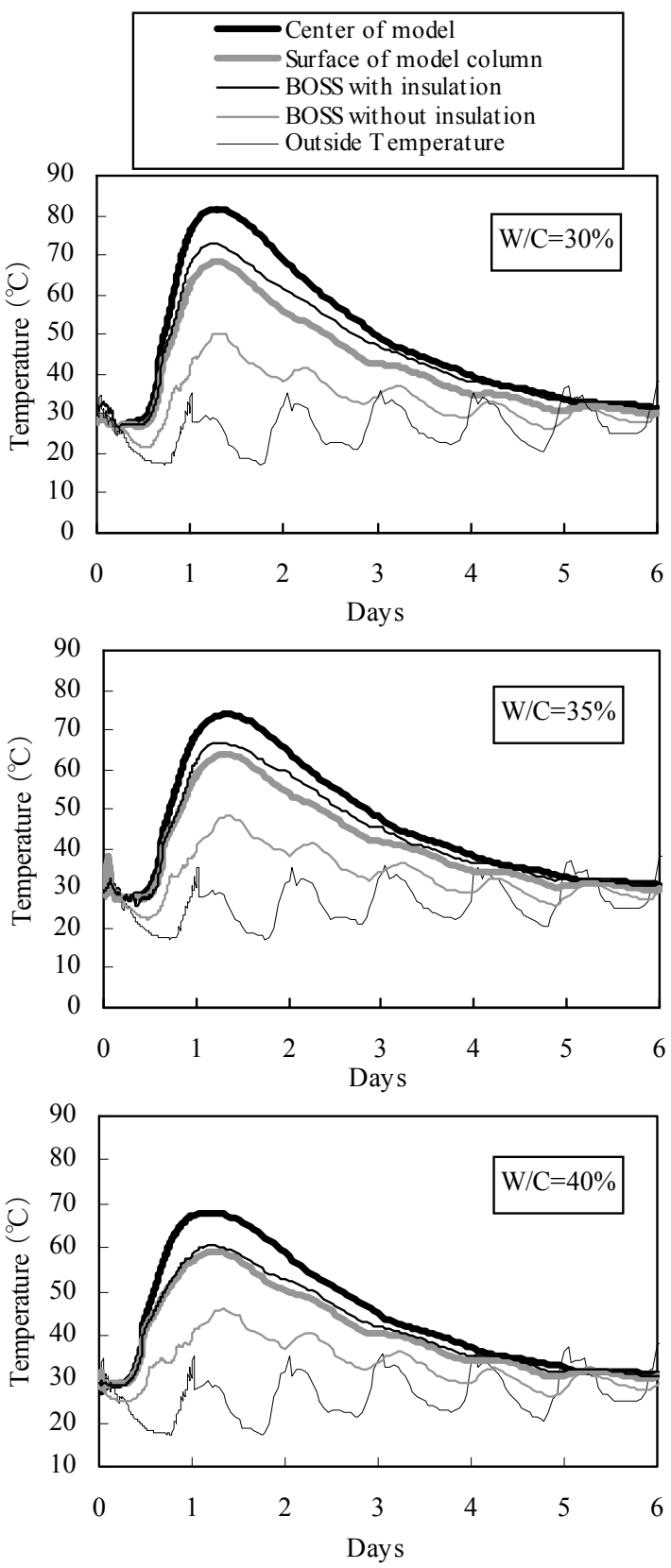

Fig. 10 Temperature histories of the model wall and BOSS specimens.
The compressive strength of cores sampled from the center and the surface of the model column are shown in Fig. 11, where no significant difference in compressive strength can be seen with respect to the sampling position. The results of the 3-way variance analysis of water-cement ratio, the sampling height and sampling position are shown in Table 11. Core strength is 1 percent significant with respect to water-cement ratio and 5 percent to sampling height, but not significant to the sampling position.

The 28-day compressive strengths of the BOSS specimens with and without insulation are shown in Fig. 12, where no significant difference can be seen. The results of the 3-way variance analysis of water-cement ratio, sampling height and presence of insulation, are shown in Table 12. Both the water-cement ratio and sampling height is 1 percent significant level to the BOSS strength. Because the sampling height was found to be significant to both core strength and BOSS strength, the sampling position should be specified in the estimation of concrete strength in structures. The presence of insulation resulted in a difference in the maximum temperature of 15 to 20 degrees, but was not significant to BOSS strength. This may suggest that the thermal insulation of the BOSS specimen, giving an equal tempera-

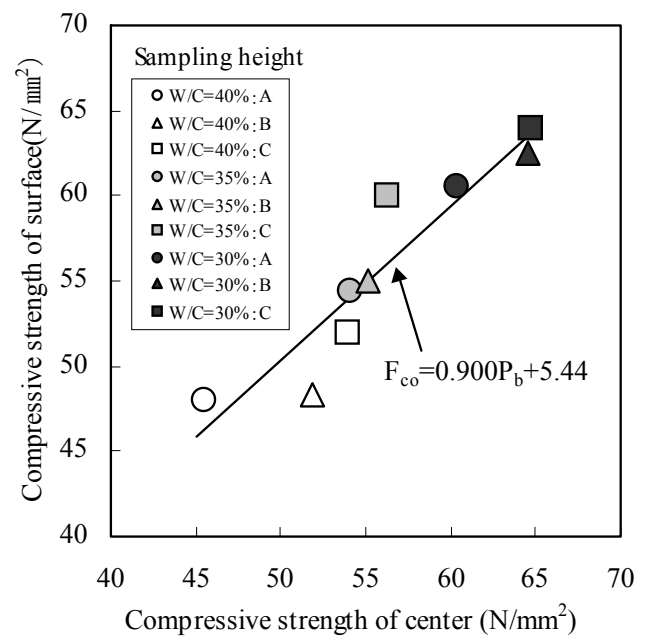

Fig. 11 Relationship of core strengths sampled from the center and surface parts.

Table 11 Variance analysis of core strength.

\begin{tabular}{|c|c|r|r|r|r|c|}
\hline Parameters & $\begin{array}{c}\text { Square sum } \\
\text { of deviation }\end{array}$ & $\begin{array}{c}\text { Degree of } \\
\text { freedom }\end{array}$ & Mean square & F-value & P-value & Result \\
\hline W/C : A & 497.79 & 2 & 248.90 & 115.8103 & 0.0003 & $* *$ \\
\hline Sampling position : B & 0.08 & 1 & 0.08 & 0.0372 & 0.8564 & $*$ \\
\hline Height : C & 65.83 & 2 & 32.92 & 15.3163 & 0.0133 & $*$ \\
\hline $\mathrm{A} \times \mathrm{B}$ & 4.83 & 2 & 2.43 & 1.1291 & 0.4085 & \\
\hline $\mathrm{A} \times \mathrm{C}$ & 6.80 & 4 & 1.70 & 0.7909 & 0.5872 & \\
\hline $\mathrm{B} \times \mathrm{C}$ & 7.39 & 2 & 3.69 & 1.7193 & 02892 & \\
\hline Error & 8.6 & 4 & 2.15 & & & \\
\hline Total & 591.34 & 17 & & & &
\end{tabular}


Table 12 Variance analysis of BOSS strength.

\begin{tabular}{|c|r|r|r|r|r|r|}
\hline Parameters & $\begin{array}{c}\text { Square sum } \\
\text { of deviation }\end{array}$ & $\begin{array}{c}\text { Degree of } \\
\text { freedom }\end{array}$ & Mean square & F-value & P-value & Result \\
\hline W/C : A & 272.80 & 2 & 136.40 & 195.6359 & 0.0001 & $* *$ \\
\hline Thermal insulation : B & 0.80 & 1 & 0.80 & 1.1506 & 0.3438 & $*$ \\
\hline Height : C & 50.49 & 2 & 25.25 & 36.2104 & 0.0027 & $* *$ \\
\hline $\mathrm{A} \times \mathrm{B}$ & 0.57 & 2 & 0.28 & 0.4072 & 0.6903 & \\
\hline $\mathrm{A} \times \mathrm{C}$ & 6.67 & 4 & 1.67 & 2.3928 & 0.2094 & \\
\hline $\mathrm{B} \times \mathrm{C}$ & 9.55 & 2 & 4.78 & 6.8494 & 0.0511 & \\
\hline Error & 2.79 & 4 & 0.70 & & & \\
\hline Total & 343.68 & 17 & & & & \\
\hline
\end{tabular}

$: 1$ percent significant, $*: 5$ percent significant

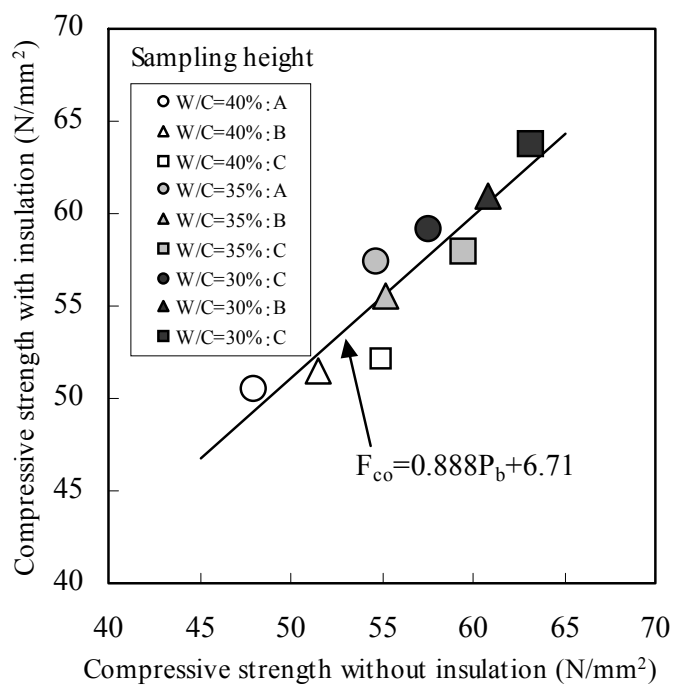

Fig. 12 Relationship of BOSS specimen strengths with and without thermal insulation.

ture history to that of the concrete structure, is not necessary to estimate concrete strength in structures.

The relationships of the maximum temperature of the model column, 28-day core strength and BOSS strength, are shown in Fig. 13. The maximum temperatures of core specimens and BOSS specimens ranged from 59 to $82^{\circ} \mathrm{C}$ and from 46 to $73^{\circ} \mathrm{C}$, respectively, while no significant difference in strength was found between specimens of both types. The relationships of 28-day strength of BOSS and core specimens and the strength under the standard curing are shown in Fig. 14. The strengths of BOSS and core specimens, both at water-cement ratios of 0.35 and 0.40 , were approximately 98 percent of the 28-day strength of the standard curing specimens. These strengths were about the upper limit reported in the previous study(Masuda et al 2000), while they were approximately 85 percent, almost the average value, at the water-cement ratio of 0.3 .

The relationship between BOSS strength, insulation and non-insulation averages, core strength, and the average of samples from the center and the surface, is shown in Fig. 15. A high correlation was found also in the case of high-strength concrete. When the data ob-

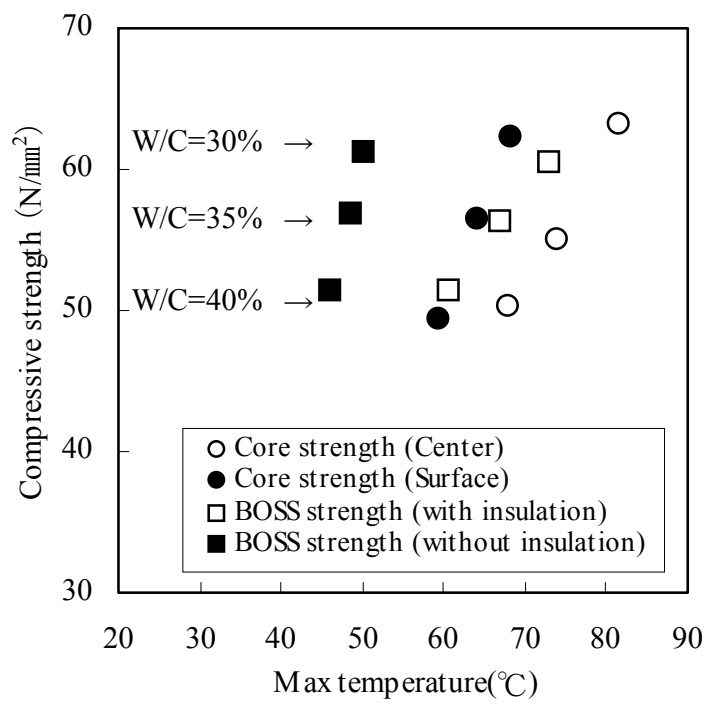

Fig. 13 Dependence of core and BOSS strength on the maximum temperature.
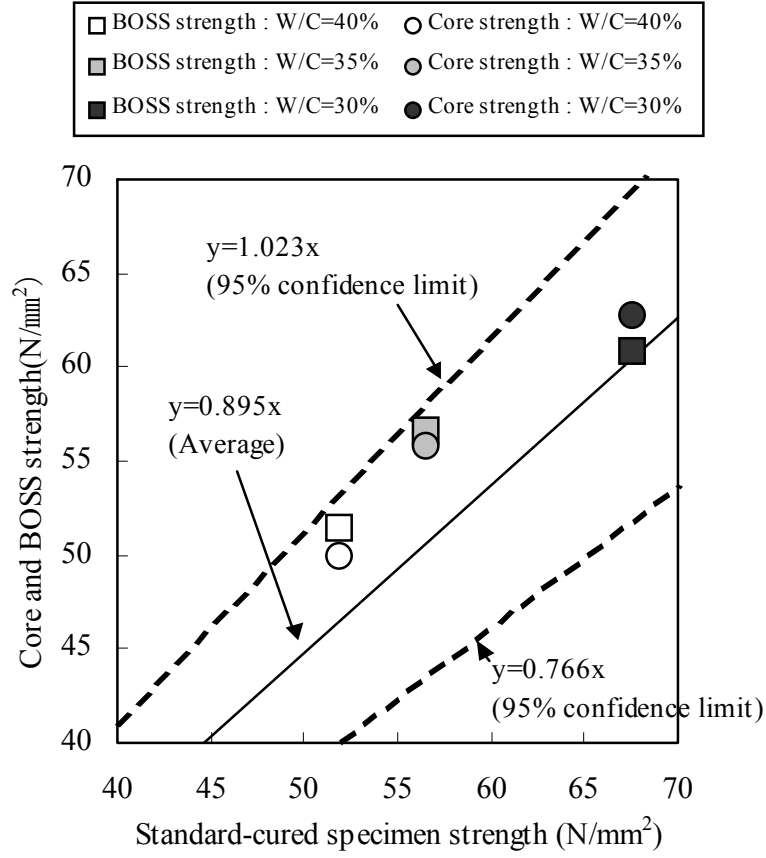

Fig. 14 Core and BOSS strength and standard-cured specimen strength (Masuda et al 2000). 
tained in the previous studies(Shinozaki et al $1992,1996,1998,1999)$ is combined with the data obtained in the series I and II experiments, as shown in Fig. 16, a regression equation can be worked out as

$$
\boldsymbol{F}_{\boldsymbol{c b}}=1.012 \boldsymbol{P}_{b^{-1}}-88
$$

Both the gradient and the intercept of equation (7) change slightly from the original regression equation (5) as a result of introducing the new data. Since the gradient of the regression equation is approximately 1.0 , it may be written as

$$
\boldsymbol{F}_{c b}=1.0 \boldsymbol{P}_{\boldsymbol{b}},
$$

where $\boldsymbol{F}_{\boldsymbol{c} b}$ is the estimated concrete strength in structure $\left(\mathrm{N} / \mathrm{mm}^{2}\right)$ and $\boldsymbol{P}_{\boldsymbol{b}}$ is the BOSS compressive strength $\left(\mathrm{N} / \mathrm{mm}^{2}\right)$. The intercept can be estimated by taking equation (7) into account,

$$
\boldsymbol{F}_{c b}=1.0 \boldsymbol{P}_{b}-\boldsymbol{\alpha} / \boldsymbol{P}_{b},
$$

where $\boldsymbol{\alpha}$ is a constant of approximately $40 \mathrm{~N} / \mathrm{mm}^{2}$. For a better estimation of concrete strength in structure, equation (7) may be applied, while for general purposes, a simple formula (9) can be used.

\section{Summary and conclusions}

Major experimental results executed with the proposed BOSS method can be summarized as follows.

(1) BOSS strength of normal concrete was influenced by water-cement ratio and sampling height with a significance level of 0.01 and 0.05 , respectively, showing a similar tendency to the dependency of core strength.

(2) BOSS strength of high-strength concrete was influenced by the water-cement ratio and sampling height with a significance level of 0.01 , each showing a similar tendency to the dependency of core strength. Presence of insulation for the BOSS mold showed no significance with respect to the BOSS strength.

(3) A high correlation was found between the BOSS strength and the core strength in both normal and high-strength concrete. It is very likely for the proposed equation $\boldsymbol{F}_{c b}=1.0 \boldsymbol{P}_{b}-\alpha / \boldsymbol{P}_{b}$ to be able to estimate the compressive strength of concrete in structures.

As a consequence, estimation of compressive strength of concrete in structures using BOSS specimens, placed at the same time, same place and subsequently cured under the same environment as those of the structure, can be executed without harming the main load-baring members, like NDT, in a sufficiently precise and reliable manner like destructive tests. Furthermore, installation of BOSS specimens in structures will enable estimations of not only compressive strength in structures but also mixture proportions and durability parameters such as carbonation depth, initial chloride content and subsequent chloride ingress, showing the possibility of

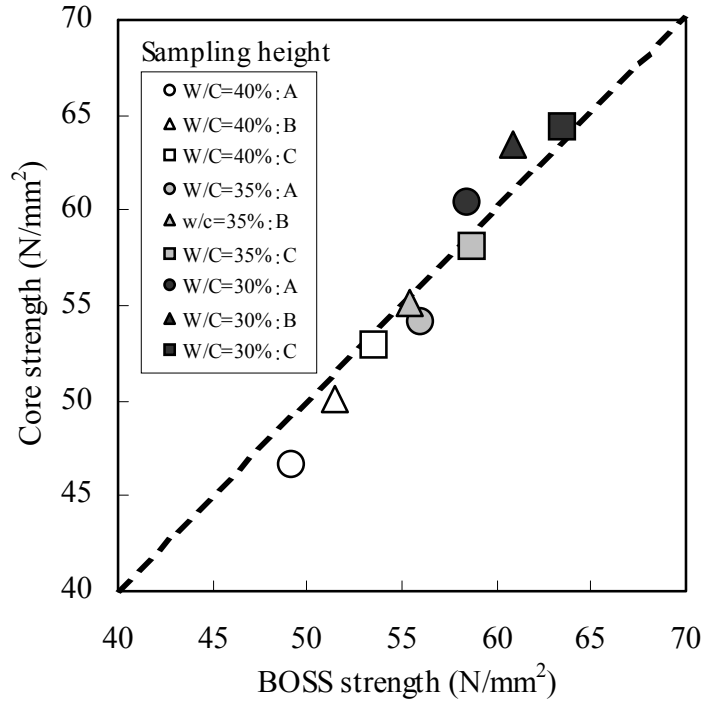

Fig. 15 Relationship between Boss strength and core strength.

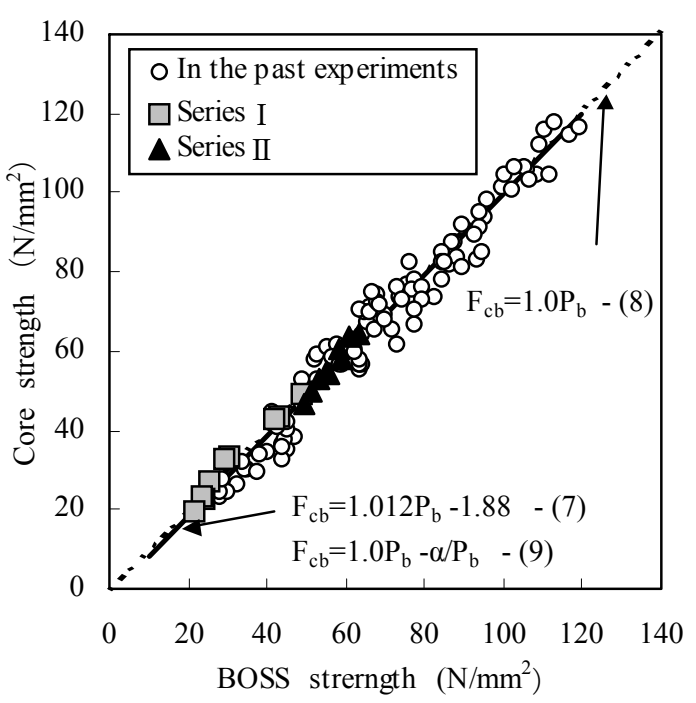

Fig. 16 Correlation of Boss strength and core strength obtained in this experiment and in the past experiments.

(Shirayama et al 1986,1991 Shinozaki et al 1987,1992,1996,1998,1999)

non-destructive and comprehensive estimation of concrete quality in structures of buildings and public works.

\section{Acknowledgments}

The authors wish to express their sincere thanks to Mr. H. Jitousono and H. Imaizumi of the Ube-Mitsubishi Cement Research Institute, Mr. K. Watanabe of the Technical Research Institute, Mitsubishi Construction Co., Ltd, diploma students of the Ashikaga Institute of Technology, and Mr. H. Watanabe and H. Hashimoto of the Koriyama factory of Tohoku Ryoko Concrete Co., Ltd for their kind assistance to this project.

The authors would also like to express their special thanks to the late Dr. T. Hiraga for his valuable advice. 


\section{References}

Aragane, N., Masuda, Y., Yasuda, M. and Nakamura, S. (1998). "Strength properties of high-strength concrete using low-heat portland cement." JCA Proceedings of Cement and Concrete, No. 52, 910-915, (in Japanese).

Kunimoto, M., Uasa, N., Kasai, Y. and Matsui, I. (2000). "Study on compressive strength test by small size cores." Annual Report of JCI, 22, 427-432, (in Japanese).

Masuda, Y., Sato, S. and Tomosawa, F. (2000). "Strength development of high-strength concrete in structure and proportioning strength." J. Struct. Constr. Eng., AIJ, No. 537, 13-20, (in Japanese).

Shirayama, K., Shinozaki, T. and Hirokawa, K. (1986). "Assessment of compressive strength of concrete in structures by the protuberant specimen method." Review of the 40th General Meeting / Technical Session. The Cement Association of Japan, 218-221.

Shirayama, K., Kemi, T., Hiraga, T., Shinozaki, T., Shinozawa, K. and Hirokawa, K. (1986). "Study on evaluation about structural concrete strength with convex specimen." Preprint of Annual Conference of AIJ, 137-138, (in Japanese).

Shinozaki, T., Shirayama, K. and Hiraga, T. (1987). "Study of assessment of compressive strength of concrete by the split specimen method." Review of the 41st General Meeting / Technical Session. The Cement Association of Japan, 234-237.

Shirayama, K., Shinozaki, T. and Hiraga, T. (1991). "Development and application of new test method for evaluating concrete strength in structure.", 2nd International Symposium Quality Control of Concrete Structures, Ghent Belgium, 439-448.
Shinozaki, T., Hiraga, T., Abe, K. and Shirayama, K. (1992). "Assessment of concrete strength in structure by BOSS specimen." Preprint of Annual Conference of AIJ, 1157-1158, (in Japanese).

Shinozaki, T., Umemoto, M., Hiraga, T., Itatani, T., Abe, K. and Sirayama, K. (1996). "Assessment of concrete strength in structure by BOSS specimen." Preprint of Annual Conference of AIJ, 691-692, (in Japanese).

Shinozaki, T., Itatani, T., Umemoto, M. and Shirayama, K. (1998). "Assessment of concrete strength in structure by BOSS specimen." JCI, Proceeding of Symposium on the Quality Control of Concrete, 69-76, (in Japanese).

Shinozaki, T., Itatani, T., Umemoto, M. and Yasoshima, H. (1999). "Study on assessment of concrete strength in structure by use of BOSS specimen." Toda Technical Research Report 25, 83-90, (in Japanese).

Soshiroda, T., Voraputhaporn, K. (2000). "Quality inspection methods of concrete in structures by nondestructive testing Part 3." J. Struct.Constr.Eng., AIJ, No. 538, 35-41, (in Japanese).

Shinozaki, T., Fujii, K., Jidousono, H., Watanabe, K., Kemi, T. and Shirayama, K. (2002). "Assessment of concrete strength in structure by BOSS specimen." AIJ J. Technol. Des. No. 15, 31-34, (in Japanese).

Shinozaki, T., Fujii, K., Kemi, T. and Shirayama, K. (2002). "Assessment of strength in structure of high-strength concrete by BOSS specimen." AIJ J. Technol. Des. No. 16, 41-44, (in Japanese).

Terada, K., Tanigawa, Y., Nakagome, A. and Sawara, H. (2001). "Estimation method for strength of concrete in structure by small-Sized cores." Concrete Technology, 39, 27-32, (in Japanese). 